\title{
Produção e caracterização de anticorpos monoclonais contra uma cepa do herpesvírus bovino tipo 1 defectiva na glicoproteína $\mathrm{C}(\mathrm{gC})$
}

\author{
Production and characterization of monoclonal antibodies to a bovine herpesvirus type 1 strain defective \\ on the glycoprotein $\mathrm{C}$
}

\author{
Evandro Reinoldo Winkelmann ${ }^{\mathrm{I}}$ Letícia Frizzo da Silva ${ }^{\mathrm{I}}$ Sandra Vanderli Mayer ${ }^{\mathrm{I}}$ \\ Ketty Cristina Mazzutti ${ }^{\mathrm{I}}$ Rudi Weiblen ${ }^{\mathrm{I}}$ Eduardo Furtado Flores ${ }^{\mathrm{I} *}$
}

\section{RESUMO}

A maioria dos anticorpos monoclonais (AcMs) já produzidos contra o herpesvírus bovino tipo 1 (BoHV-1) reage com a glicoproteína $C(\mathrm{gC})$, um antígeno abundante $e$ imunodominante presente no envelope viral. Com o objetivo de produzir AcMs com outras especificidades protéicas, antígenos de uma cepa do BoHV-1 defectiva no gene da $\mathrm{gC}$ foram utilizados para a imunização de camundongos BALB/c. Após fusão e seleção de 54 hibridomas resistentes ao meio seletivo HAT, foram obtidos três clones (1F1, $2 H 4$ e 4D7) secretores de imunoglobulinas da classe IgG2a, que reagiram com antígenos da cepa homóloga. Os AcMs reagiram com antígenos virais nas técnicas de imunofluorescência (IFA) e imunoperoxidase (IPX) em diluições de até 1:640 (sobrenadante de cultivo) e 1:20.000 (fluído ascítico). Os três AcMs apresentaram um espectro amplo de reatividade, reagindo com antígenos de 14 herpesvírus isolados de doença respiratória ou genital (provavelmente BoHV-1) e com 17 isolados de doença neurológica (supostamente BoHV-5), e apresentaram atividade neutralizante em níveis variáveis contra todos esses isolados. A especificidade protéica dos AcMs não pode ser determinada diretamente, pois nenhum deles reagiu com proteínas virais na técnica de Western blot. Por outro lado, os três AcMs reagiram em IFA com células infectadas com uma cepa do BoHV-5 defectiva nas glicoproteínas E, I e proteína US9, o que exclui estes antígenos como possíveis alvos dos AcMs. Por exclusão ( $g C, g E, g I)$ e pela sua forte atividade neutralizante, os AcMs são provavelmente direcionados contra epitopos conservados de outras glicoproteínas do envelope viral que contêm epitopos neutralizantes: a $g B$ e/ou $g D$. Pelo seu alto título de reação $e$ pelo amplo espectro de reatividade, esses AcMs possuem potencial aplicação em técnicas diagnósticas. Além disso, podem ser úteis para o mapeamento de epitopos neutralizantes conservados nas glicoproteínas do envelope.

Palavras-chave: herpesvírus bovino, BoHV-1, BoHV-5, anticorpos monoclonais, neutralização.

\begin{abstract}
Most monoclonal antibodies (MAbs) already produced against bovine herpesvirus type 1 (BoHV-1) react with glycoprotein $C(\mathrm{gC})$, an abundant and immunodominant antigen present on the viral envelope. In order to obtain MAbs with other protein specificities, antigens of a BoHV-1 gC-negative strain were used to immunize BALB/c mice. After fusion and selection of 54 HAT-resistant hybridomas, three clones have been obtained (1F1, $2 \mathrm{H} 4$ and 4D7) that secrete IgG2a antibodies reacting to BoHV-1 antigens. These MAbs reacted with viral antigens in immunofluorescence (IFA) and immunoperoxidase (IPX) in dilutions up to 1:640 (hybridoma supernatants) and 1:20.000 (ascitis fluid). The three MAbs showed a wide spectrum of reactivity, recognizing antigens of 14 herpesviruses isolated from respiratory or genital disease (supposedly BoHV-1) and with 17 isolates of neurological disease (likely $\mathrm{BoHV}-5$ ) and displayed varied levels of neutralizing activity against all these viruses. The protein specificity could not be demonstrated directly as none of the MAbs bound to viral antigens in Western blot. On the other hand, the three MAbs reacted with cells infected with a BoHV5 strain defective in glycoproteins $g E$ and $g I$, demonstrating they are directed to other viral proteins. By exclusion ( $g C, g E$ and $g I$ ) and due to their neutralizing activity, these MAbs are probably directed to conserved epitopes on other envelope glycoproteins harboring neutralizing epitopes: $g B$ or $g D$. In this sense, besides being useful for diagnosis purposes, these MAbs may be very useful for mapping neutralizing epitopes in these glycoproteins.
\end{abstract}

Key words: bovine herpesvirus, BoHV-1, BoHV-5, monoclonal antibodies, virus neutralization.

\section{INTRODUÇÃO}

O herpesvírus bovino tipo 1 (BoHV-1) é considerado um dos principais patógenos de bovinos

ISetor de Virologia, Departamento de Medicina Veterinária Preventiva (DMVP), Universidade Federal de Santa Maria (UFSM), 97105-900, Santa Maria, RS, Brasil. E-mail: flores@ccr.ufsm.br. * Autor para correspondência. 
pela repercussão sanitária e econômica da infecção em rebanhos de leite e corte. A rinotraqueíte infecciosa bovina (infectious bovine rhinotracheitis, IBR) - uma das manifestações clínicas da infecção pelo BoHV-1 - é uma das principais enfermidades infecto-contagiosas de bovinos e possui distribuição mundial. Além de enfermidade respiratória, a infecção pelo BoHV-1 também está associada com doença reprodutiva em fêmeas (vulvovaginite [IPV], infertilidade temporária, abortos) e em machos (balanopostite [IBP]) (KAHRS, 2001).

O BoHV-1 é membro da família Herpesviridae, subfamília Alphaherpesvirinae, gênero Varicellovirus; é um vírus envelopado e possui uma molécula de DNA de fita dupla linear de $137 \mathrm{~kb}$ como genoma (ROIZMAN et al., 1992). Com base em padrões de restrição enzimática do genoma e na reatividade com anticorpos monoclonais (AcMs), os isolados do BoHV-1 podem ser classificados em dois subtipos: BoHV-1.1, isolados geralmente mais virulentos e associados com doença respiratória (IBR); e BoHV1.2 , vírus menos virulentos e freqüentemente identificados em doença genital (IPV/IBP) (METZLER et al., 1986; FRIEDLI \& METZLER, 1987).

O genoma do BoHV-1 codifica mais de 70 produtos, entre os quais 10 a 12 são glicoproteínas do envelope. Essas glicoproteínas desempenham importantes funções nas interações entre os vírions e as células hospedeiras e constituem-se em importantes alvos para anticorpos neutralizantes (TIKOO et al., 1995). As glicoproteínas $\mathrm{gB}, \mathrm{gD}$ e provavelmente a $\mathrm{gH}$, gK e gL são essenciais para a replicação dos alfaherpesvírus em cultivo celular. As glicoproteínas $\mathrm{gC}, \mathrm{gG}, \mathrm{gI}$ e gE são dispensáveis para o ciclo replicativo em cultivo, mas desempenham funções importantes nas interações com o hospedeiro e provavelmente são necessárias à sobrevivência do vírus na natureza (KAASHOEK et al., 1998).

Anticorpos monoclonais (AcMs) produzidos contra antígenos do BoHV-1 têm sido utilizados com diversas finalidades, incluindo a identificação e caracterização de polipeptídeos virais (MARSHAL et al., 1986; METZLER et al., 1986), identificação e diferenciação entre subtipos do BoHV-1 e entre o BoHV-1 e o BoHV-5 (METZLER et al., 1986; FRIEDLI \& METZLER, 1987; SOUZA et al., 2002), mapeamento de epitopos neutralizantes (COLLINS et al., 1984; DUBUISSON et al., 1992; ABDELMAGIB et al., 1995) e uso em diversas técnicas de diagnóstico, entre outras.

A maioria dos AcMs produzidos com antígenos do BoHV-1 reagem contra a glicoproteína $\mathrm{C}$ $(\mathrm{gC})$. A gC é a glicoproteína mais abundante presente no envelope viral, forma protusões na superfície dos vírions e parece estar envolvida na ligação do vírus com os receptores celulares (LIANG et al., 1991). O fato de a $\mathrm{gC}$ ser muito abundante e imunodominante tem dificultado a obtenção de AcMs contra outras proteínas virais. AcMs com outras especificidades protéicas podem ser úteis para diversos estudos da biologia e das interações do vírus com o sistema imunológico, além de apresentarem aplicação potencial em técnicas de diagnóstico.

O presente trabalho teve como objetivo a produção de AcMs com especificidades protéicas que não a gC. Para isso, camundongos BALB/c foram imunizados com antígenos de uma cepa do BoHV-1 defectiva no gene que codifica esta glicoproteína. Os AcMs obtidos foram caracterizados com relação ao seu isotipo, espectro de reatividade, capacidade neutralizante, especificidade protéica e aplicações potenciais em técnicas diagnósticas.

\section{MATERIAL E MÉTODOS}

\section{Células e vírus}

Células de linhagem de rim bovino (linhagem CRIB, FLORES \& DONIS, 1995) foram utilizadas para a multiplicação de vírus, testes de imunofluorescência (IFA), imunoperoxidase (IPX) e soroneutralização (SN). As células foram cultivadas em meio essencial mínimo Eagle $^{a}$ (MEM) suplementado com $10 \%$ de soro bovino fetal $^{\mathrm{b}}$ (FBS), 10.000UI ${ }^{-1}$ de penicilina ${ }^{\mathrm{b}}, 0,2 \mathrm{~g} \mathrm{l}^{-1}$ de estreptomicina $^{\mathrm{b}}$ e $2,5 \mathrm{mg} \mathrm{l}^{-1}$ de fungizona ${ }^{\mathrm{c}}$. As células Sp2 de mieloma, obtidas na Universidade Federal de Pelotas (UFPel), foram propagadas em meio RPMI, suplementado com $15 \%$ de FBS, $50 \mu \mathrm{g} \mathrm{l}^{-1}$ de 8 azaguanina $^{\mathrm{d}}, 1 \mathrm{mM}$ de piruvato de sódio ${ }^{\mathrm{d}}, 2 \mathrm{mM}$ de Lglutamina $^{\mathrm{d}}, 0,01 \%$ de 2 -mercaptoetanol ${ }^{\mathrm{d}} \mathrm{e}$ antibióticos. A cepa de BoHV-1 defectiva no gene da glicoproteína C (IBRVdltkdlgC, FLORES et al., 1993) e a cepa parental de BoHV-5 Los Angeles foram cedidas pelo Dr. Fernando A. Osorio (Department of Veterinary and Biomedical Sciences, University of Nebraska, Lincoln, NE, USA). A cepa de BoHV-1 defectiva nas glicoproteínas gE e gI e na proteína US9 (EVI-88/95 recombinante) foi fornecida pelo Dr Paulo Roehe (IPVDF/Fepagro, Eldorado do Sul, RS). A cepa IBRVdltkdlgC foi utilizada para produção de antígeno e imunização dos camundongos. A origem e caracterização das amostras de BoHV-1 e BoHV-5 utilizadas para estudar o espectro de reatividade dos AcMs e nos testes de SN foram descritas anteriormente (SOUZA et al., 2002; OLDONI et al., 2004).

Produção de antígeno e imunização dos camundongos - A cepa IBRVdltkdlgC foi clonada três 
vezes pela técnica de ensaio de placa (MAHY \& KANGRO, 1996), propagada e utilizada para infectar células CRIB para a produção de antígeno. As células foram infectadas com uma multiplicidade de infecção de aproximadamente $1 \mathrm{DICC}_{50} /$ célula (dose infectante para $50 \%$ do cultivo celular). Quando o efeito citopático (ECP) atingiu aproximadamente $80 \%$ do tapete celular (aproximadamente 24 horas após a inoculação), o sobrenadante foi coletado. As células presentes no sobrenadante e o restante do tapete celular foram coletados por centrifugação a $12.000 \mathrm{x} \mathrm{g} \mathrm{a} 4^{\circ} \mathrm{C}$ por 15 minutos. Em seguida, o sobrenadante foi descartado e o sedimento celular foi submetido a três ciclos de congelamento $\left(-80^{\circ} \mathrm{C}\right)$ e descongelamento e submetido a uma nova centrifugação. $O$ sedimento contendo os debris celulares foi então descartado e o sobrenadante $\left(200 \mu \mathrm{l}\right.$ - correspondente a um frasco de $150 \mathrm{~cm}^{2}$ de células infectadas - aproximadamente $10^{8}$ células) foi armazenado a $-80^{\circ} \mathrm{C}$. Para a primeira imunização, o concentrado de vírus e proteínas virais foi misturado com um volume equivalente de adjuvante completo de Freund $^{\mathrm{d}}$. Nas imunizações seguintes $(14,28$ e 42 dias após a primeira imunização), utilizou-se o antígeno viral $(200 \mu \mathrm{l})$ associado com adjuvante incompleto de

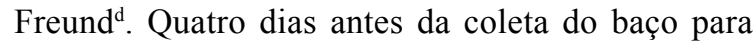
fusão, foram administrados $200 \mu 1$ de antígeno sem adjuvante. Todas as imunizações foram realizadas pela via intraperitonial (ip). Para a imunização e produção de líquido ascítico, foram utilizados camundongos da linhagem endocruzada BALB/c com idades entre $45 \mathrm{e}$ 60 dias, adquiridos da Embrapa (CNPSA, Concórdia$\mathrm{SC})$.

Fusão celular, seleção e triagem de hibridomas, produção de líquido ascítico - Os procedimentos de fusão, seleção e triagem dos hibridomas secretando AcMs foram realizados de acordo com protocolos descritos por OLDONI et al. (2004). A presença de AcMs no sobrenadante dos cultivos foi testada por imunofluorescência indireta (IFA). Para isso, foram utilizadas células CRIB infectadas com cepa IBRVdltkdlgC e células nãoinfectadas. As colônias de hibridomas que secretaram AcMs reagentes nos testes de IFA foram clonadas por diluição limitante, expandidas, testadas novamente para a produção de $\mathrm{AcMs}$ e estocadas a $-196^{\circ} \mathrm{C}$ em nitrogênio líquido. Para os hibridomas secretores de AcMs contra o BoHV-1, foi produzido líquido ascítico em camundongos $\mathrm{BALB} / \mathrm{c}$, de acordo com o protocolo descrito por OLDONI et al. (2004).

Caracterização dos AcMs - Os AcMs produzidos foram caracterizados com relação à classe e à subclasse de imunoglobulina, ao título de reação em IFA e IPX, ao espectro de reatividade e à atividade neutralizante com isolados de campo e especificidade protéica. Isotipo: a classe e a subclasse das imunoglobulinas foram determinadas com um kit comercial, de acordo com instruções do fabricante ${ }^{e}$. Título de reação: o título de AcMs no sobrenadante do cultivo de hibridomas e no líquido ascítico foi determinado testando-se diluições crescentes dos AcMs como anticorpo primário na técnica de IFA e IPX. Espectro de reatividade: os três AcMs foram testados frente a células infectadas com um painel de isolados de campo de herpesvírus de doença respiratória ou genital (supostamente BoHV-1) e de doença neurológica (supostamente BoHV-5). Células CRIB infectadas com cada isolado foram testadas por IFA, utilizando-se cada AcM como anticorpo primário e um anticorpo anti-IgG de camundongo conjugado com fluoresceína como anticorpo secundário. Os AcMs 2F9 e 2G10 (OLDONI et al., 2004) foram utilizados como controle positivo. Atividade neutralizante: foi investigada pela técnica de soroneutralização (SN), realizada de acordo com OLDONI et al. (2004), testandose diluições crescentes de cada AcM (fluído ascítico) frente a 100 DICC $_{50}$ do BoHV-1 IBRVdltkdlgC ou dos isolados de herpesvírus (Tabela 1). Especificidade protéica: a especificidade protéica dos AcMs foi investigada pela técnica de Western blot, realizada de acordo com OLDONI et al. (2004), utilizando-se cada AcM como anticorpo primário. Alternativamente, investigou-se a reatividade dos AcMs na técnica de IFA com células infectadas com cepas do BoHV-5 defectivas nas glicoproteínas gE e gI e proteína US9.

\section{RESULTADOS}

Após quatro fusões sem sucesso, a quinta fusão entre esplenócitos de camundongos BALB/c imunizados com antígenos da cepa IBRVdlTKdlgC do BoHV-1 com células de mieloma resultou em 54 hibridomas resistentes ao meio seletivo HAT. O sobrenadante do cultivo de três hibridomas $(1 \mathrm{~F} 1,2 \mathrm{H} 4$, 4D7) reagiu em IFA especificamente com células infectadas com o BoHV-1, mas não com células nãoinfectadas. O sobrenadante dos demais hibridomas reagiu também com células não-infectadas ou não apresentou reação positiva.

Inicialmente, o sobrenadante dos cultivos destes hibridomas foi testado por IFA contra antígenos da cepa mutante $\mathrm{gC}(-)$ (IBRVdltkdlgC) e contra a cepa parental $\mathrm{gC}(+)$ (Los Angeles). Os três AcMs reagiram com antígenos de ambas as cepas, confirmando serem realmente direcionados contra outras proteínas que não a $\mathrm{gC}$ (não mostrado). Estes hibridomas foram então clonados, expandidos e congelados a $-196^{\circ} \mathrm{C}$. 
Tabela 1 - Reatividade ${ }^{1}$ e atividade neutralizante ${ }^{2}$ dos anticorpos monoclonais com isolados de campo e cepas padrão de herpesvírus bovino tipo 1 (BoHV-1) e 5 (BoHV-5).

\begin{tabular}{|c|c|c|c|c|c|c|c|}
\hline \multirow{3}{*}{ Cepa } & \multirow{3}{*}{ Quadro clínico ou origem da amostra } & \multicolumn{6}{|c|}{ Anticorpos monoclonais } \\
\hline & & \multicolumn{2}{|c|}{$1 \mathrm{~F} 1$} & \multicolumn{2}{|c|}{$2 \mathrm{H} 4$} & \multicolumn{2}{|c|}{ 4D7 } \\
\hline & & IFA & $\mathrm{SN}$ & IFA & $\mathrm{SN}$ & IFA & $\mathrm{SN}$ \\
\hline Los Angeles & $\mathrm{IBR}^{\mathrm{a}}$ & $+^{\mathrm{b}}$ & $40^{\mathrm{c}}$ & + & 40 & + & 160 \\
\hline IBRVdlTKdlgIII $^{\mathrm{d}}$ & Cepa recombinante (IBR) & + & 1280 & + & 320 & + & 320 \\
\hline Cooper & IBR & + & 20 & + & 10 & + & 10 \\
\hline EVI $123 / 98$ & IBR & + & 20 & + & 40 & + & 80 \\
\hline SV 265/96 & IBR & + & 40 & + & 40 & + & 80 \\
\hline SV453/93 & IBR & + & 20 & + & 10 & + & 10 \\
\hline LAM & IBR & + & 20 & + & 40 & + & 80 \\
\hline LAM US9 $^{-\mathrm{e}}$ & Cepa recombinante (IBR) & + & 320 & + & 160 & + & 80 \\
\hline SV $56 / 90$ & $\mathrm{IPV}^{\mathrm{f}}$ & + & 160 & + & 160 & + & 80 \\
\hline SV371/05 & IBR & + & 20 & + & 40 & + & 20 \\
\hline CE $05-18$ & Sêmen & + & 20 & + & 20 & + & 40 \\
\hline ILAG 01 - 2420 & Sêmen & + & 20 & + & 40 & + & 80 \\
\hline CE $05-63$ & Sêmen & + & 40 & + & 40 & + & 20 \\
\hline CIAG 04 - 1428 & Sêmen & + & 40 & + & 80 & + & 40 \\
\hline $97 / 613$ & Encefalite & + & 20 & + & 10 & + & 10 \\
\hline A663 & Encefalite & + & $\leq 10$ & + & 10 & + & 10 \\
\hline EVI 340/96 & Encefalite & + & $\leq 10$ & + & 40 & + & 80 \\
\hline P-160/87 & Encefalite & + & 40 & + & 80 & + & 40 \\
\hline P-169/97 & Encefalite & + & 20 & + & 40 & + & 40 \\
\hline $\mathrm{RP}$ & Encefalite & + & 40 & + & 20 & + & 20 \\
\hline SV 136/88 & Encefalite & + & 10 & + & 10 & + & 10 \\
\hline EVI-88/95 & Encefalite & + & 80 & + & 160 & + & 40 \\
\hline EVI-88/95 $\mathrm{gE}^{-}, \mathrm{gI}^{-}, \mathrm{US}^{-\mathrm{g}}$ & Cepa recombinante (Encefalite) & + & 80 & + & 20 & + & 40 \\
\hline SV106 & Encefalite & + & 20 & + & 40 & + & 40 \\
\hline SV507/99 & Encefalite & + & 10 & + & 10 & + & 10 \\
\hline SV642/99 & Encefalite & + & 10 & + & 10 & + & 10 \\
\hline SV47/05 & Encefalite & + & 160 & + & 40 & + & 80 \\
\hline SV609/03 & Encefalite & + & 160 & + & 40 & + & 80 \\
\hline SV198/05 & Encefalite & + & 80 & + & 80 & + & 80 \\
\hline SV41/06 & Encefalite & + & 20 & + & 10 & + & 10 \\
\hline SV437/04 & Encefalite & + & 20 & + & 20 & + & 10 \\
\hline
\end{tabular}

${ }^{1}$ Testada pela técnica de imunofluorescência indireta (IFA).

${ }^{2}$ Testada pela técnica de soroneutralização (SN).

${ }^{\text {a }}$ Rinotraqueíte infecciosa bovina.

${ }^{\mathrm{b}}$ Reação positiva.

${ }^{\mathrm{c}}$ Títulos expressos como a recíproca da maior diluição capaz de neutralizar a replicação viral.

${ }^{\mathrm{d}}$ Cepa com deleção dos genes da timidina quinase e da glicoproteína gC.

${ }^{\text {e }}$ Cepa com deleção do gene da proteína US9.

${ }^{\mathrm{f}}$ Vulvovaginite pustular infecciosa.

${ }^{\mathrm{g}}$ Cepa com deleção dos genes das glicoproteínas gE, gI e da proteína US9.

Posteriormente, produziu-se fluido ascítico com cada um dos hibridomas pela inoculação intraperitoneal em camundongos. A caracterização descrita a seguir utilizou tanto o sobrenadante de cultivos quanto o fluido ascítico respectivo (Tabela 2).

O resumo da caracterização dos AcMs está apresentado na tabela 2. Os três AcMs contêm imunoglobulinas da classe $\mathrm{G}$, subclasse $2 \mathrm{a}$ (IgG2a). O título de anticorpos determinado pelas técnicas de IFA e IPX variou de 160 a 640 no sobrenadante dos cultivos de hibridomas e entre 10.000 e 20.000 no fluido ascítico. Os três AcMs reagiram tanto em IFA como em IPX realizadas em cultivos celulares. Tentativas de utilizar esses AcMs em imunoistoquímica (IHC) em cortes histológicos provenientes de tecidos positivos para o BoHV-1 fixados em formol tamponado a $10 \%$ e 
Tabela 2 - Caracterização de anticorpos monoclonais (AcMs) produzidos contra antígenos de uma cepa de herpesvírus bovino tipo 1 (BoHV1) defectiva na glicoproteína gC (IBRVdlTKdlgIII).

\begin{tabular}{|c|c|c|c|c|c|c|c|c|}
\hline \multirow[b]{2}{*}{$\mathrm{AcM}$} & \multirow[b]{2}{*}{ Isotipo } & \multicolumn{2}{|c|}{ Título $^{\mathrm{a}}$} & \multirow{2}{*}{$\begin{array}{l}\text { Reação } \\
\text { em IFA }^{\text {b }}\end{array}$} & \multirow{2}{*}{$\begin{array}{l}\text { Reação } \\
\text { em IPX }\end{array}$} & \multirow{2}{*}{$\begin{array}{l}\text { Western } \\
\text { blot }\end{array}$} & \multirow{2}{*}{$\begin{array}{l}\text { Especificidade } \\
\text { protéica }\end{array}$} & \multirow{2}{*}{$\begin{array}{c}\text { Atividade } \\
\text { neutralizante }\end{array}$} \\
\hline & & $\begin{array}{l}\text { Sobrenadante de } \\
\text { cultivo }\end{array}$ & Líquido ascítico & & & & & \\
\hline $1 \mathrm{~F} 1$ & $\mathrm{IgG} 2 \mathrm{a}$ & 320 & 17.500 & $+^{\mathrm{d}}$ & + & $-\mathrm{e}$ & \multirow{3}{*}{ 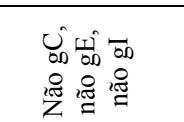 } & $+(1280)^{f}$ \\
\hline $2 \mathrm{H} 4$ & $\operatorname{IgG} 2 \mathrm{a}$ & 160 & 10.000 & + & + & - & & $+(320)$ \\
\hline 4D7 & $\operatorname{IgG} 2 \mathrm{a}$ & 640 & 20.000 & + & + & - & & $+(320)$ \\
\hline
\end{tabular}

${ }^{a}$ Títulos expressos como a recíproca da maior diluição em que se observou reação positiva na IFA.

${ }^{\mathrm{b}}$ Técnica de imunofluorescência indireta.

${ }^{c}$ Técnica de imunoperoxidase indireta.

${ }^{\mathrm{d}}$ Reação positiva.

${ }^{\text {e }}$ Reação negativa.

${ }^{\mathrm{f}}$ Títulos expressos como a recíproca da maior diluição do AcM (líquido ascítico) capaz de impedir a replicação viral. Os AcMs foram testados pela técnica de soroneutralização utilizando a cepa homóloga IBRVdlTKdlgIII.

parafinados resultaram infrutíferas (dados não mostrados). Da mesma forma, nenhum dos AcMs reagiu com proteínas virais na técnica de Western blot. Tentativas de renaturar as proteínas após a separação por SDS-PAGE e transferência para membrana não tiveram sucesso.

Como os AcMs não reagiram com proteínas virais na técnica de Western blot, recorreu-se a outra abordagem na tentativa de se determinar a sua especificidade protéica. Para isso, os AcMs foram testados na técnica de IFA com células infectadas com uma cepa do BoHV-5 defectiva nas glicoproteínas E e I e na proteína US9. Novamente, os três AcMs reagiram positivamente, demonstrando serem direcionados contra outras proteínas, que não a gE, gI e US9 (Tabela 2).

Os três AcMs reagiram com células infectadas com cada um dos 14 isolados de doença respiratória ou genital e com 17 isolados de doença neurológica (Tabela 1). O sobrenadante dos cultivos de hibridoma não apresentou atividade neutralizante detectável na técnica de SN. No entanto, o fluido ascítico dos três AcMs apresentou atividade neutralizante contra a cepa homóloga em títulos de até 1280 (1F1) e 320 (2H4, 4D7). O teste desses AcMs frente aos outros 30 isolados de campo ou cepas-padrão evidenciou atividade neutralizante, em títulos variáveis, contra todos (Tabela 1).

\section{DISCUSSÃO}

A grande maioria dos AcMs produzidos contra o BoHV-1, até o presente, são direcionados contra a glicoproteína $\mathrm{C}(\mathrm{gC})$. Isso deve-se à grande abundância dessa glicoproteína nos vírions e pelo fato de a gC ser altamente imunogênica (BABIUK et al., 1987; LIANG etal., 1991). OLDONI et al. (2004) relataram a produção de 11 AcMs contra uma cepa brasileira de $\mathrm{BoHV}-5$, oito dos quais são específicos para a $\mathrm{gC}$, e os demais sem especificidade determinada. No presente trabalho, a estratégia de imunização de camundongos com antígenos de uma cepa de BoHV-1 defectiva na gC permitiu a obtenção de AcMs contra outras proteínas virais.

A especificidade protéica desses AcMs não pode ser determinada, pois nenhum deles reagiu com proteínas virais na técnica de Western blot. Esses AcMs, provavelmente, são direcionados contra epitopos que sofreram desnaturação pelo SDS e mercapto-etanol utilizados na solubilização das proteínas e/ou durante a separação das mesmas por SDS-PAGE (CHAPSAL \& PEREIRA, 1988). Tentativas de renaturar as proteínas na membrana para favorecer a ligação dos AcMs também foram frustradas (dados não mostrados). Pelo tipo de imunógeno utilizado proteínas totais de células infectadas - esses anticorpos poderiam ser direcionados para quaisquer proteínas virais, estruturais ou não-estruturais. A utilização da técnica de rádio-imuno precipitação (METZLER et al., 1986) poderia ser uma alternativa para se identificar as proteínas que induziram a proliferação dos clones de linfócitos B secretores desses AcMs.

A atividade neutralizante verificada indica que os AcMs são direcionados contra antígenos de superfície dos vírions, provavelmente glicoproteínas envolvidas nos estágios iniciais de infecção (LIANG et al., 1991). Além disso, a ampla reatividade e atividade neutralizante demonstrada contra vários isolados de campo do BoHV-1 e do BoHV-5 indicam que os anticorpos reconhecem epitopos altamente 
conservados nestas proteínas. A reatividade desses AcMs com células infectadas com uma cepa de BoHV5 defectiva nas glicoproteínas E ( $\mathrm{gE}$ ) e I (gI) (além da US9) descarta também essas duas glicoproteínas como possíveis alvos dos AcMs. A exclusão das glicoproteínas C, E e I como possíveis alvos, aliada com a atividade neutralizante de amplo espectro, sugere que os AcMs são direcionados contra uma das outras glicoproteínas do envelope que induzem anticorpos com atividade neutralizante, a gB e/ou gD (BABIUK et al., 1987).

A glicoproteína D (gD) possui 417 aminoácidos e três resíduos de açúcar $(75 \mathrm{kDa})$ e é altamente conservada entre isolados de campo do BoHV-1 (Van DRUNEN LITTEL-Van DER HURK \& BABIUK, 1986). Esta glicoproteína é essencial para a replicação do vírus em cultivo celular e está envolvida na fusão e penetração dos vírions nas células, estágios imediatamente subseqüentes à ligação aos receptores, que parece ser mediada predominantemente pela $\mathrm{gC}$ (DUBUISSON et al., 1992). Dentre os AcMs direcionados às glicoproteínas do envelope, os AcMs contra $\mathrm{aD}$ apresentam a maior atividade neutralizante independente de complemento e inibem a adsorção e penetração viral (DUBUISSON et al., 1992; ABDELMAGID et al., 1995). AcMs com atividade neutralizante contra a gD têm sido utilizados no mapeamento de epitopos neutralizantes presentes nesta glicoproteína (ABDEMALGID et al., 1995).

Outro possível alvo dos AcMs é a glicoproteína $\mathrm{B}(\mathrm{gB})$. A gB é uma das principais glicoproteínas do envelope do BoHV-1, possui 932 aminoácidos e uma massa de $130 \mathrm{kDa}$ após a glicosilação, apresentando dois produtos de clivagem, de 74 e 55kDa(Van DRUNEN LITTEL-Van DER HURK \& BABIUK, 1986). A gB é essencial para a replicação do BoHV-1 em cultivo celular e participa dos estágios iniciais de infecção, juntamente com as glicoproteínas gC e gD (LIANG et al., 1991). Anticorpos monoclonais contra epitopos conservados na $\mathrm{gB}$ possuem forte atividade neutralizante (LIANG et al., 1991).

Os altos títulos neutralizantes observados no presente estudo sugerem que os AcMs sejam direcionados contra a $\mathrm{gD}$, já que anticorpos contra a gB geralmente possuem menor atividade neutralizante na ausência de complemento em relação a $\mathrm{gD}$ (DUBUISSON et al., 1992). É interessante observar que os maiores títulos neutralizantes dos três AcMs foram verificados contra a cepa defectiva na $\mathrm{gC}$. Uma possível explicação para esse achado é que a cepa $\mathrm{gC}$ (-) foi a cepa utilizada como imunógeno. Além disso, essa alta atividade neutralizante (comparando com títulos neutralizantes de 10 contra outros isolados; Tabela 1) pode ter outra explicação. Tem sido demonstrado que a principal proteína de ligação aos receptores é a $\mathrm{gC}$, mas que a $\mathrm{gD}$ pode também participar neste processo. Assim, em vírus defectivos na $\mathrm{gC}$, a $\mathrm{gD}$ assume o papel de ligação aos receptores (LIANG et al., 1991). Conseqüentemente, a cepa defectiva na $\mathrm{gC}$ seria mais sensível à neutralização por anticorpos anti-gD. Nas outras cepas, o efeito seria menor, pois elas possuem a $\mathrm{gC}$, através da qual os vírus ligariam-se aos receptores. Além disso, esses achados reforçam a importância da gD nos estágios iniciais de infecção, conjuntamente com a gC, provavelmente participando da ligação e/ou penetração celular.

A reatividade e a atividade neutralizante dos AcMs com a totalidade dos isolados de BoHV-1 e BoHV-5 testados demonstra que os anticorpos são direcionados contra epitopos bem conservados entre esses vírus. As glicoproteínas $\mathrm{gB}$ e gD estão entre as mais conservadas do BoHV-1, ao contrário da $\mathrm{gC}$, que apresenta considerável variabilidade sobretudo em seu terço amino-terminal (CHOWDHURY, 1995).

Se realmente forem direcionados contra as glicoproteínas B ou D, esses AcMs podem ser úteis para o mapeamento de epitopos que são alvos de anticorpos neutralizantes nestas glicoproteínas. A produção in vitro de mutantes de escape de neutralização pelos AcMs e o posterior seqüenciamento dos epitopos mutados podem fornecer informações importantes sobre as regiões dessas glicoproteínas envolvidas nas interações iniciais com os receptores celulares. Em resumo, a imunização de camundongos BALB/c com antígenos de uma cepa do BoHV-1 defectiva na glicoproteína $\mathrm{C}(\mathrm{gC})$ permitiu a obtenção de AcMs contra outras proteínas virais. Embora a sua especificidade não tenha sido determinada, os experimentos realizados sugerem que estes anticorpos são direcionados contra a gB e/ou gD. Se confirmado, estes AcMs podem ser úteis para o mapeamento de epitopos neutralizantes nestas glicoproteínas, além de serem úteis para outras aplicações, como o diagnóstico e a pesquisa.

\section{FONTES DE AQUISIÇÃO:}

${ }^{a}$ Cultilab, Campinas, SP, Brasil.

${ }^{\mathrm{b}}$ Gibco-BRL, Rockville, MD, USA.

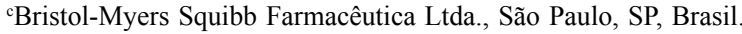
dSigma Chemical Co., St. Louis, MO, USA.

eMouse Type Isotyping kit, BioRad, Hercules, CA, USA.

\section{COMITÊ DE ÉTICA E BEM-ESTAR}

Todos os procedimentos com os animais foram realizados de acordo com as normas do COBEA (lei número 6.638 de 8 de maio de 1979) e aprovados pelo Comitê de Ética 
e Bem-Estar Animal da Universidade Federal de Santa Maria (UFSM) sob parecer $n^{\circ} 42 / 2006$.

\section{REFERÊNCIAS}

ABDELMAGID, O.Y. et al. Fine mapping of bovine herpesvirus 1 (BHV-1) glycoprotein D (gD) neutralizing epitopes by typespecific monoclonal antibodies and sequence comparison with BHV-5 gD. Virology, v.206, p.242-253, 1995.

BABIUK, L.A. et al. Protection of cattle from bovine herpesvirus type 1 (BHV-1) infection by immunization with individual viral glycoproteins. Virology, v.159, p.57-66, 1987.

CHAPSAL, J.M.; PEREIRA, L. Characterization of epitopes on native and denatured forms of herpes simplex virus glycoprotein B. Virology, v.164, p.427-434, 1988.

CHOWDHURY, S.I. Molecular basis of antigenic variation between the glycoproteins $\mathrm{C}$ of respiratory bovine herpesvirus 1 (BHV-1) and neurovirulent BHV-5. Virology, v.213, p.558568,1995 .

COLLINS, J.K. et al. Neutralizing determinants defined by monoclonal antibodies on polypeptides specified by bovine herpesvirus 1. Journal of Virology, v.52, p.403-409, 1984.

DUBUISSON, J. et al. Mechanisms of bovine herpesvirus type 1 neutralization by monoclonal antibodies to glycoproteins gI, gIII and gIV. Journal of General Virology, v.73, p.20312039, 1992.

FLORES, E.F. et al. Efficacy of a deletion mutant bovine herpesvirus-1 (BHV-1) vaccine that allows serologic differentiation of vaccinated from naturally infected animals. Journal of Veterinary Diagnostic Investigation, v.5, p.534540,1993

FLORES, E.F.; DONIS, R.O. Isolation of a mutant MDBK cell line resistant to bovine viral diarrhea virus infection due to a block in viral entry. Virology, v.208, p.565-575, 1995.

FRIEDLI, K.; METZLER, A.E. Reactivity of monoclonal antibodies to proteins of a neurotropic bovine herpesvirus 1 (BHV-1) strain and to proteins of representative BHV-1 strains. Archives of Virology, v.94, p.109-122, 1987.
KAASHOEK, M.J. et al. Virulence, immunogenicity and reactivation of bovine herpesvirus 1 mutants with a deletion in the $\mathrm{gC}, \mathrm{gG}, \mathrm{gI}, \mathrm{gE}$, or in both $\mathrm{gI}$ and $\mathrm{gE}$ gene. Vaccine, v.16, p.802-809, 1998.

KAHRS, R.F. Infectious bovine rhinotracheitis and infectious vulvovaginitis. In: Viral diseases of cattle. 2.ed.

Ames: Iowa State University, 2001. p.159-170.

LIANG, X. et al. Bovine herpesvirus 1 attachment to permissive cells is mediated by its major glycoproteins gI, gII and gIV. Journal of Virology, v.65, p.1124-1132, 1991.

MARSHALL, R.L. et al. Characterization of envelope proteins of infectious bovine rhinotracheitis virus (bovine herpesvirus 1) by biochemical and immunological methods. Journal of Virology, v.57, p.745-753, 1986.

MAHY, B.W.J.; KANGRO, H.O. Virology methods manual. San Diego, CA: Academic, 1996. 374p.

METZLER, A.E. et al. Bovine herpesvirus 1: molecular and antigenic characteristics of variant viruses isolated from calves with neurological disease. Archives of Virology, v.87, p.205217,1986 .

OLDONI, I. et al. Production and characterization of monoclonal antibodies to a Brazilian bovine herpesvirus type 5 (BHV-5). Brazilian Journal of Medical and Biological Research, v.37, p.213-221, 2004.

ROIZMAN, B. et al. The family Herpesviridae: an update. Archives of Virology, v.123, p.425-488, 1992.

SOUZA, V.F. et al. Caracterização de amostras de herpesvírus tipo 1 (BHV-1) e 5 (BHV-5) com anticorpos monoclonais. Pesquisa Veterinária Brasileira, v.22, p.13-18, 2002.

TIKOO, S.K. et al. Bovine herpesvirus 1 (BHV-1): biology, pathogenesis and control. Advances in Virus Research, v.45, p.191-215, 1995 .

Van DRUNEN-LITTEL-Van DER HURK, S.; BABIUK, L.A. Synthesis and processing of bovine herpesvirus 1 glycoproteins. Journal of Virology, v.59, p.401-410, 1986. 